\title{
Energy Management Strategy Using Equivalent Consumption Minimization Strategy for Hybrid Electric Vehicles
}

\author{
Fazhan Tao, ${ }^{1,2}$ Longlong Zhu, ${ }^{1}$ Baofeng Ji, ${ }^{1,2}$ Pengju Si, ${ }^{1,2}$ and Zhumu Fu $\mathbb{D}^{1,2}$ \\ ${ }^{1}$ School of Information Engineering, Henan University of Science and Technology, Luoyang 471000, China \\ ${ }^{2}$ Henan Key Laboratory of Robot and Intelligent Systems, Henan University of Science and Technology, Luoyang 471000, China
}

Correspondence should be addressed to Zhumu Fu; fuzhumu@haust.edu.cn

Received 13 October 2020; Revised 24 November 2020; Accepted 7 December 2020; Published 18 December 2020

Academic Editor: Xingwang Li

Copyright (C) 2020 Fazhan Tao et al. This is an open access article distributed under the Creative Commons Attribution License, which permits unrestricted use, distribution, and reproduction in any medium, provided the original work is properly cited.

\begin{abstract}
In this paper, an energy management strategy for electric vehicles equipped with fuel cell (FC), battery (BAT), and supercapacitor (SC) is considered, aiming at improving the whole performance under a framework of vehicle to network application. In detail, based on wavelet transform and equivalent consumption minimization strategy (ECMS), the demand power of vehicles is optimized to enhance the lifespan of fuel cell, fuel economy, and dynamic performance of electric vehicles. The wavelet transform is used to separate the high-frequency power in order to provide a peak power and recycle the braking energy. The equivalent consumption minimization strategy is used to distribute the low-frequency power to fuel cell and battery for minimizing the hydrogen consumption. Obtained results are studied using an advanced vehicle simulator, and its effectiveness of the strategy is confirmed, which provides a fundamental control method for the IOV application.
\end{abstract}

\section{Introduction}

As the development of automobile industry has reached a certain level [1-4], it also leads to some issues, such as environmental pollution, global warming, energy crisis, and the growing number of traffic congestion and accidents. Many further aspirations are emerging to make the vehicle safer, more eco-friendly, and more intelligent. Meantime, since the technology of Internet of vehicles has achieved many developments rapidly [5-13], it provides a better way to optimize a control strategy for HEVs by sharing a package of data consisting of relevant information related to the vehicle status and the road condition.

As for the energy management strategy for hybrid electric vehicles equipped with FC, BAT, and SC (FCHEV), it has an important role in the performance of hybrid electric system, which can be roughly classified into rule-based EMS and optimization-based EMS from the optimization aspects [14-23]. Rule-based energy strategies are developed based on rules or maps extracted from the designed splitting methods $[13,19,20]$. In order to solve the cruising range of three-energy plug-in HEV, Zhang et al. [19] proposed a rulebased fuzzy control strategy to realize a hierarchical control based on driving pattern recognition, whose results show that the proposed method can effectively extend the PHEV cruising range and the energy management efficiency. In [20], dual-energy (FC+BAT) and triple-energy $(\mathrm{FC}+\mathrm{BAT}+\mathrm{SC})$ management strategies are considered using the fuzzy control method, achieving the energy distribution between the required power and multiple energy sources for four standard driving cycles and compared with the original power tracking strategy in ADVISOR. A doublefuzzy logic controller is proposed [14] to decouple power of the vehicle and to ensure the economy of fuel consumption of the vehicle. Considering rule-based EMSs cannot achieve optimal power distribution, it is constrained to a certain extent.

Therefore, the optimization-based EMS has been proposed. The optimization-based EMS includes global optimal strategies and real-time optimal strategies, which has been studied by researchers and engineers, including 
dynamic programming, genetic algorithm, model control prediction, and Pontryagin's minimum principle $[17,18,20,21]$. In [21], a novel real-time energy management strategy based on ECMS is proposed, and the equivalent factor is adaptive to the drive conditions to catch energy-saving opportunities during the trip, which improves the fuel economy. Zhang et al. proposed a minimum hydrogen consumption equivalent strategy, adding an energy storage system to the original FC system for compensating peak demand power and recycling braking energy to improve the economy of hydrogen consumption [22]. In [23], in order to improve fuel economy and adaptability of various driving conditions for online energy management, a hierarchical model predictive control strategy is proposed, the upper controller realizes optimal torque distribution, and the lower controller ensures the tracking performance of engine output torque for the distributed torque from the upper controller.

As for the aforementioned results, most of them focus on HEVs and existing high burden on computation for online application. As for the considered FCHEV in this paper, FC regarded as the main energy source cannot recover braking energy and needs to be combined with energy storage system. Consider a high energy density of BAT and higher power density of SC, and both of them are combined as an energy storage system. Meantime, considering the different characteristic of the existing three power sources, how to design one low burden computation and an effective EMS is important for the IOV application. Wavelet transform (WT) is a very efficient signal processing method, and it can effectively separate the low-frequency and high-frequency parts of the required power signal, which is supposed to significantly protect the fuel cell from required power fluctuations, and can be implemented online easily. In this paper, in order to tackle unreasonable energy distribution and low energy utilization rate among various energy sources, energy management strategy based on wavelet transform and equivalent consumption minimization strategy is proposed for the FCHEV.

The rest of the paper is organized as follows: the models of the main component's description and the topology and mathematical models of FCHEV are stated in Section 2. Main results on EMS are addressed based on wavelet transform and ECMS in Section 3. In Section 4, simulation results are furnished to verify the effectiveness of the proposed strategy. Finally, Section 5 draws the conclusion of this paper.

\section{Modelling for FCHEVs}

In FCHEV, fuel cell as a primary power source through the unidirectional DC/DC converter delivers power to motor, and a battery is used as a direct energy source to directly transmit power to motor and recycle barking power. When the vehicle accelerates suddenly, supercapacitor provides peak power through bidirectional DC/DC while absorbing the braking energy of the vehicle. The model of vehicles is shown in Figure 1.
The power of a hybrid electric vehicle is provided by fuel cell, battery, and supercapacitor, and the power demand can be calculated as follows:

$$
P_{\text {req }}=\lambda_{1} P_{\mathrm{fc}}+P_{\mathrm{bat}}+\lambda_{2} P_{\mathrm{sc}} \text {, }
$$

where $P_{\text {req }}, P_{\mathrm{fc}}, P_{\mathrm{bat}}$, and $P_{\mathrm{sc}}$ represent the demand power of vehicle and the power provided by fuel cell, battery, and supercapacitor, respectively. $\lambda_{1}$ indicates the efficiency of fuel cell, and $\lambda_{2}$ indicates the efficiency of the supercapacitor.

Fuel cell converts chemical energy into electrical energy by consuming hydrogen to provide energy for vehicles. $P_{\mathrm{fc}}$ can be expressed as follows:

$$
P_{\mathrm{fc}}=\eta_{\mathrm{fc}} \times \int_{0}^{t} \frac{m_{H_{2}}(t) \times 1.4 \times 10^{8}}{3600} \mathrm{~d} t,
$$

where $m_{H_{2}}$ indicates the mass of $H_{2}, 1.4 \times 10^{8}$ indicates the heating value of $\mathrm{H}_{2}$ combustion, and $\eta_{\mathrm{fc}}$ indicates the efficiency of hydrogen combustion into power.

As for battery, $P_{\text {bat }}$ can be expressed by equation (4). In this paper, the internal resistance of the battery is ignored:

$$
P_{\text {bat }}=u \int_{0}^{t} i(t) \mathrm{d} t
$$

where $u$ indicates the voltage of battery and $i(t)$ indicates the instantaneous current of battery.

In order to prevent the battery from working excessively thereby reducing its lifetime, the SOC of battery should be kept within the operable range. The SOC of battery $\left(\mathrm{SOC}_{b a t}\right)$ is given as follows:

$$
\mathrm{SOC}_{\mathrm{bat}}=\mathrm{SOC}_{0}-\int_{0}^{t} \frac{i(t)}{\mathrm{Q}_{\mathrm{bat}}} \mathrm{d} t,
$$

where $\mathrm{SOC}_{0}$ indicates the initial SOC of the battery and $Q_{\mathrm{bat}}$ is the maximum charge of the battery.

The output voltage of the supercapacitor consists of two parts: one part is the energy released by the supercapacitor and the other part is caused by the internal resistance of the supercapacitor. The supercapacitor $\mathrm{SOC}\left(\mathrm{SOC}_{s c}\right)$ can be expressed by the following equation:

$$
\mathrm{SOC}_{\mathrm{sc}}=\mathrm{SOC}_{1}-\frac{\mathrm{Q}_{0}-\int_{0}^{t} u(t) / R_{i} \mathrm{~d} t}{\mathrm{Q}_{s c_{-} \max }},
$$

where $\mathrm{SOC}_{1}$ indicates the initial SOC of supercapacitor, $Q_{0}$ indicates the initial charge of supercapacitor, $Q_{s c_{-} \max }$ indicates the maximum charge of supercapacitor. $u(t)$ indicates the instantaneous voltage of supercapacitor, and $R_{i}$ indicates the internal resistance of supercapacitor.

\section{Energy Management Strategy for FCHEV}

Considering different characteristics of power sources of FCHEV, the supercapacitor suits to supply high-frequency components of $P_{\text {req }}$, and the fuel cell and battery are suitable to supply low-frequency components of $P_{\text {req. }}$. Therefore, an EMS is proposed in this paper, as shown in Figure 2. Firstly, the wavelet transform is utilized for decoupling $P_{\text {req, }}$, $P_{\text {high }}$ (high-frequency components of $P_{\text {req }}$ ) will be assigned 


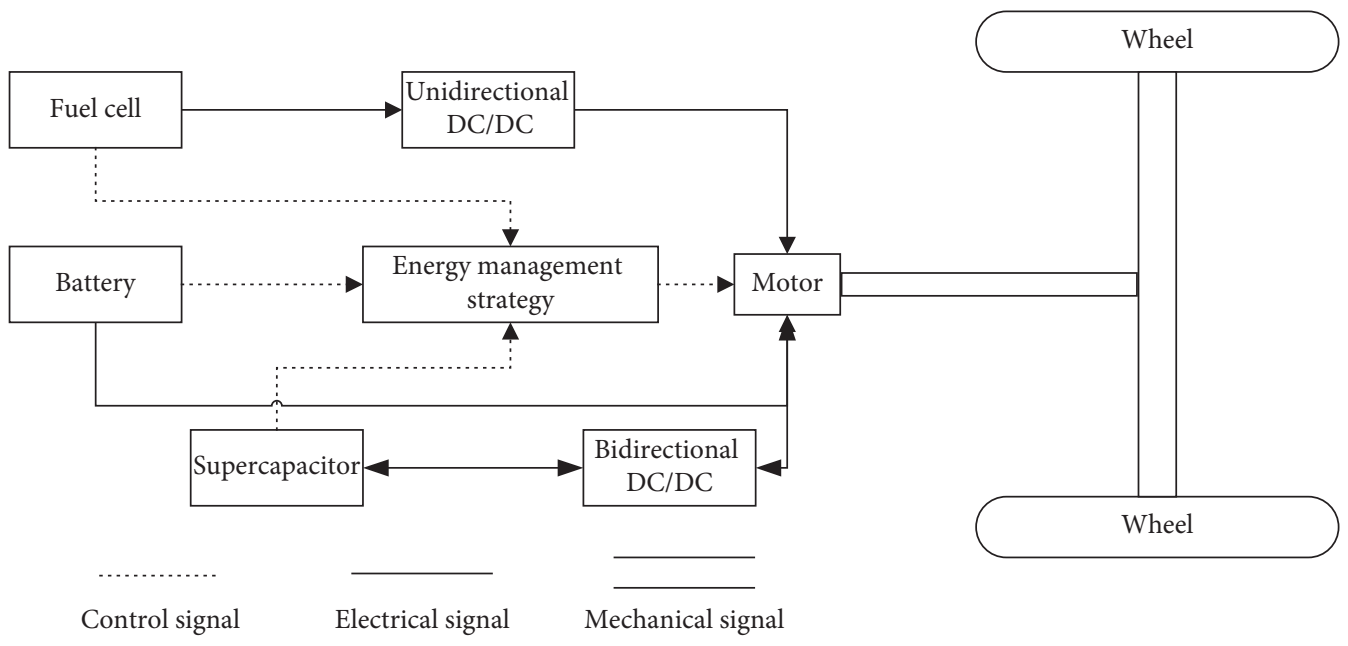

Figure 1: Power structure of HEV.

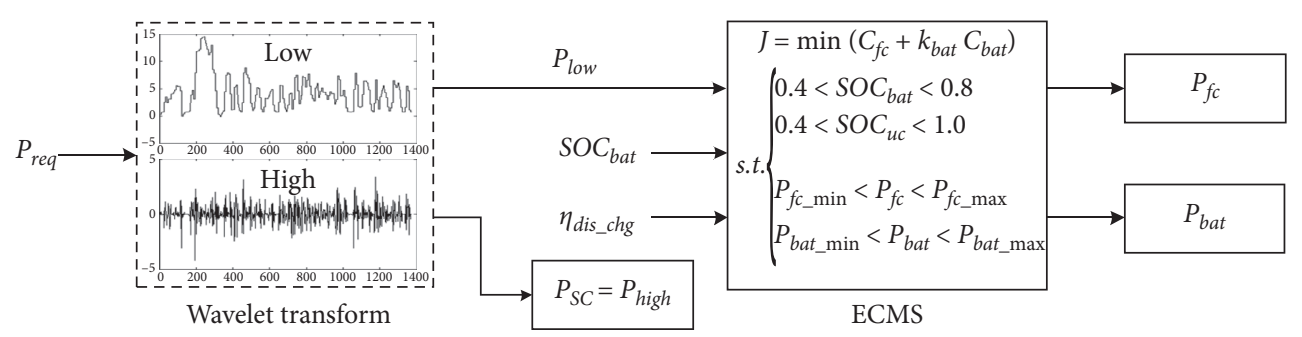

Figure 2: The structure of the proposed EMS.

to supercapacitor, and $P_{\text {low }}$ (low-frequency components of $\left.P_{\text {req }}\right)$ will be assigned to fuel cell and battery. Secondly, ECMS method is used to distribute $P_{\text {low }}$ to fuel cell and battery for minimizing the hydrogen consumption and to maintain battery in a predefined range.

Wavelet transform and inverse wavelet transform are adopted as follows:

$$
\begin{aligned}
W(\lambda, u) & =\int s(t) \frac{1}{\sqrt{\lambda}} \Psi\left(\frac{t-u}{\lambda}\right) \mathrm{d} t, \\
\lambda & =2^{j}, \\
u & =k 2^{j}, \\
k & \in Z, \\
s(t) & =\sum_{j=Z} \sum_{k=Z} W(j, k) \Psi_{(j, k)}(t),
\end{aligned}
$$

where $s(t)$ is the original signal, $\lambda$ is the scale parameter, $u$ is the position parameter, $\Psi$ is the mother wavelet, and $W$ is the wavelet coefficient.

Inspired by $[24,25]$, the energy distribution process of FCHEV is regarded as the one stationary process and, therefore, is chosen as the other wavelet to relax calculation burden on the real-time application for IOV. Hence, in this paper, Harr wavelet is chosen as follows, and the three-level
Haar wavelet decomposition and reconstruction are shown in Figure 3:

$$
\Psi(t)= \begin{cases}1, & 0 \leq t \leq 0.5 \\ 1, & 0.5<t \leq 1 \\ 0, & \text { otherwise }\end{cases}
$$

From Figure 3 , by $l_{0}(z)$ (low-pass filter) and $h_{0}(z)$ (highpass filter), $s(n)$ (original signal) is reconstructed with very slight errors based on the reconstruction filter bank. Based on the proposed method, $P_{\text {req }}$ can be obtained as follows:

$$
\left\{\begin{array}{l}
P_{\text {low }}=s_{0}(n)=P_{\mathrm{fc}}+P_{\text {bat }}, \\
P_{\text {high }}=s_{1}(n)+s_{2}(n)+s_{3}(n)=P_{\mathrm{sc}}
\end{array}\right.
$$

where $s_{0}(n)$ is the reference signal.

After the WT process, the low component of the required power needs to be further processed to determine the power distribution ratio between the fuel cell and battery. The essence of the strategy of minimum equivalent consumption is to convert the BAT and SC power into equal fuel consumption and then optimize equivalent hydrogen consumption of BAT and SC to minimize the fuel consumption of FCHEV. Therefore, the total hydrogen consumption of FCHEV including the three power sources is shown as follows:

$$
C_{m}=\min \left(C_{\mathrm{fc}}+k_{\mathrm{bat}} C_{\mathrm{bat}}\right) \text {, }
$$




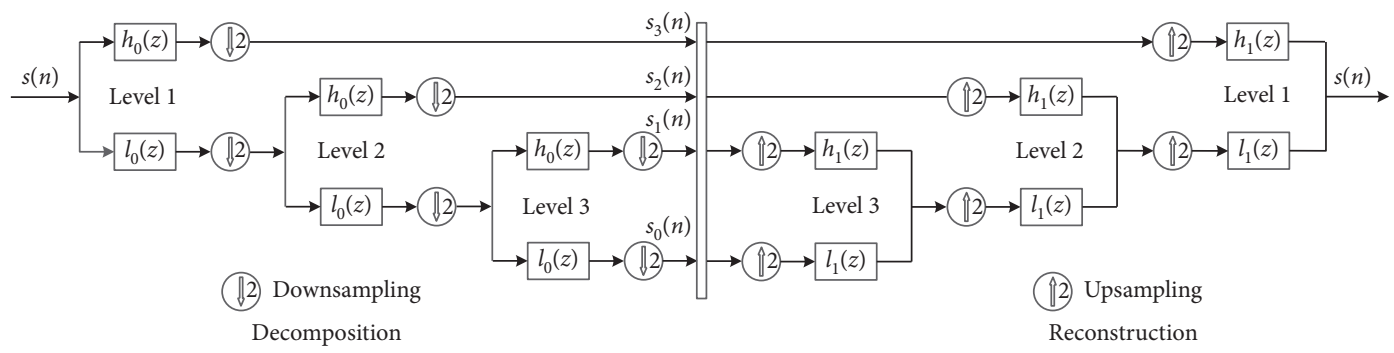

FIgURE 3: Three-level Haar wavelet decomposition and reconstruction.

where $C_{m}, C_{\mathrm{fc}}$, and $C_{\mathrm{bat}}$ represent the minimum hydrogen consumption of vehicles and hydrogen consumption of FC and $\mathrm{BAT}$ and $k_{\text {bat }}$ represents equivalent factor of the equivalent hydrogen consumption of BAT and SC. The hydrogen consumption of the fuel cell is shown as follows:

$$
C_{\mathrm{fc}}=\int_{0}^{t} \frac{i_{\mathrm{fc}}(t)}{\mathrm{NA} \times e} \mathrm{~d} t
$$

where $i_{\mathrm{fc}}(t)$ represents the current generated by the fuel cell consuming hydrogen, NA represents the Avogadro constant $6.02 \times 1023 \mathrm{~mol}^{-1}$, and $e$ means the electric quantity of electrons is $1.6 \times 10-19^{\circ} \mathrm{C}$. follows:

The hydrogen consumption of the battery is shown as

$$
C_{\text {bat }}=\int_{0}^{t} \frac{i_{\mathrm{fc}}(t) \times P_{\text {bat }}}{\mathrm{NA} \times e \times P_{\mathrm{fc}} \times \eta_{\text {dis_chg }}} \mathrm{d} t
$$

where $\eta_{\text {dis_chg }}$ indicates the charging and discharging efficiency of the battery.

The equivalent factor of the equivalent hydrogen consumption of the battery is related to SOC of battery. When the battery work in a safety range, $K_{b a t}$ can be expressed as follows:

$$
K_{\text {bat }}=1-\mu \frac{\mathrm{SOC}-0.5\left(\mathrm{SOC}_{\mathrm{bat} \text { max }}-\mathrm{SOC}_{\mathrm{bat} \text { min }}\right)}{\mathrm{SOC}_{\text {bat max }}-\mathrm{SOC}_{\text {bat min }}},
$$

where $\mathrm{SOC}_{\text {batmax }}$ and $\mathrm{SOC}_{\text {batmin }}$ represent the maximum and minimum SOC values of the battery.

Considering influence of the charging and discharging state of the battery and working range of the fuel cell on service life of the battery and fuel cell, the charging and discharging state of the battery and working range of the fuel cell are taken as constraints as follows:

$$
\left\{\begin{array}{l}
0.4<\mathrm{SOC}_{\mathrm{bat}}<0.8, \\
0.4<\mathrm{SOC}_{\mathrm{uc}}<1.0, \\
P_{\mathrm{fc} \_ \text {min }}<P_{\mathrm{fc}}<P_{\mathrm{fc} \_ \text {max }}, \\
P_{\text {bat_min }}<P_{\text {bat }}<P_{\text {bat_max }},
\end{array}\right.
$$

where $P_{\text {fc_min }}$ and $P_{\text {fc_max }}$ represent the minimum and maximum power allowed for fuel cell operation, respectively, and $P_{\text {bat_min }}$ and $P_{\text {bat_max }}$ indicate the minimum and maximum power allowed for fuel cell operation, respectively.

\section{Simulation Results}

In this section, the advanced vehicle simulator is employed to confirm the effectiveness of the proposed method. Firstly, New European Drive Cycle (NEDC), Highway Fuel Economy Test (HWFET), and Urban Dynamometer Driving Schedule (UDDS) drive cycle are the typical road conditions representing suburbs, highway, and city, respectively. Thus, the combined drive cycle (NEDC + HWFET + UDDS) is used to test the effectiveness of the proposed EMS in reducing hydrogen consumption and extending fuel cell lifespan by using MATLAB/Simulink. Vehicle speed and required power under combined drive cycle is shown in Figure 4. Main parameters and component models of FCHEV are listed in Table 1. Then, power distribution of fuel cell, battery, and supercapacitor, fuel cell power fluctuation, SOC of battery and supercapacitor, and fuel cell efficiency are given in Figures 5-8, respectively.

The power distribution of fuel cell, battery, and supercapacitor under combined drive cycle (NEDC + HWFET + UDDS) is shown in Figure 5. It is obvious from Figure 5 that the fuel cell and battery provide steady-state part of the required power, and supercapacitor supplies/absorbs the peak power rapidly when FCHEV accelerates and brakes. Thus, it is supposed to significantly improve fuel cell and battery lifespan by the proposed EMS. Meanwhile, battery and supercapacitor recycle all braking energy when the HEV brakes. From the simulation results, the proposed EMS can effectively improve the energy efficiency of the whole vehicle and extend the vehicle mileage.

In order to show the effectiveness and advantages of the proposed EMS in reducing fuel cell output power fluctuation in detail, fuel cell power fluctuation (variation in fuel cell output power per second) is shown in Figure 6. It can be seen that, with the proposed EMS, the maximum fuel cell output power fluctuation is limited within $\pm 250 \mathrm{~W} / \mathrm{s}$ and almost fuel cell output power fluctuation is concentrated in the range of $-100 \mathrm{~W} / \mathrm{s}$ to $100 \mathrm{~W} / \mathrm{s}$. With smooth output of fuel cell, its lifespan is effectively extended.

Figure 7 shows the SOC variations in battery and supercapacitor under the combined drive cycle. From Figure 7, it is clear that the proposed EMS can maintain the SOC of battery and supercapacitor in a limited range, and the battery charges and discharges with a high efficiency in this range. The proposed EMS guarantees the battery and supercapacitor always have enough power for accelerating the vehicle. 


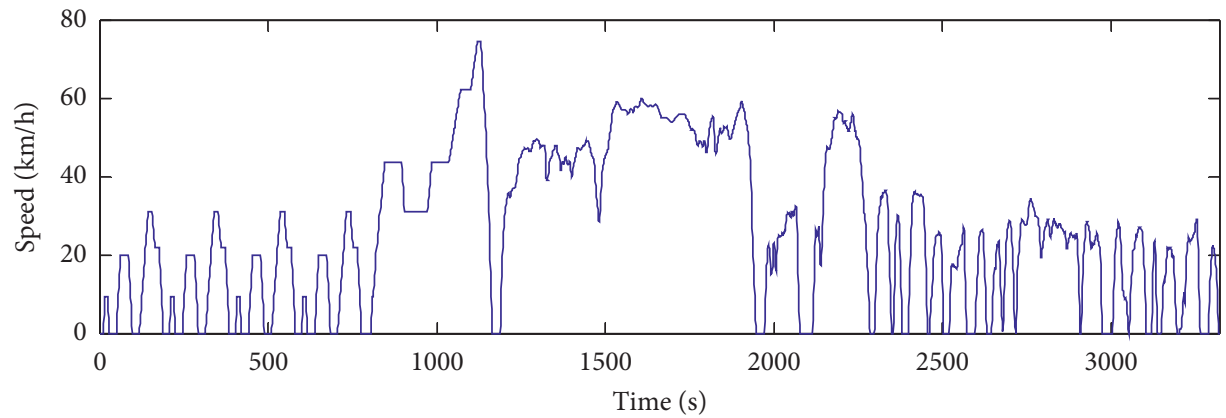

(a)

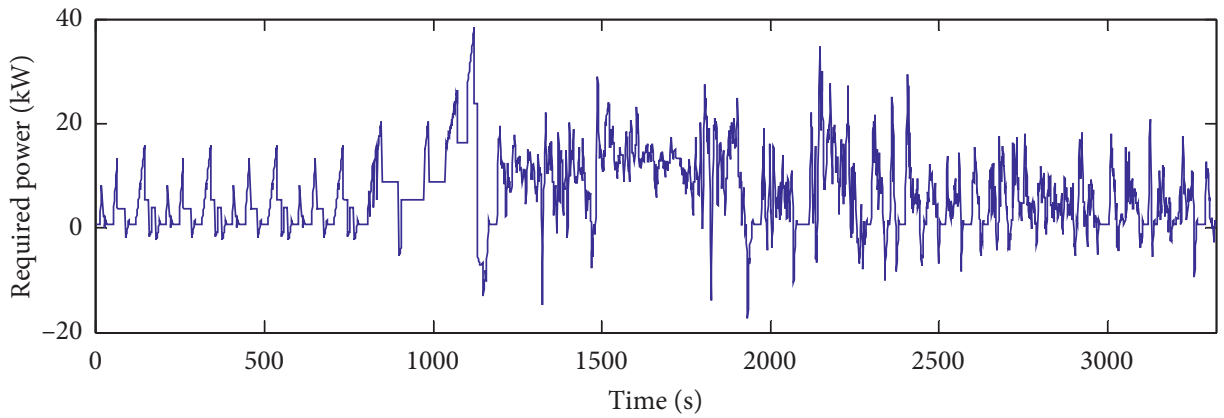

(b)

FIGURE 4: Vehicle speed and required power under combined drive cycle.

Table 1: Parameters of the vehicle model.

\begin{tabular}{lc}
\hline Parameter & Value \\
\hline Vehicle mass $(\mathrm{kg})$ & 1113 \\
Gravity constant, g $\left(\mathrm{m} / \mathrm{s}^{2}\right)$ & 9.8 \\
Rolling resistance coefficient & 0.6 \\
Aerodynamic drag coefficient & 0.3 \\
Vehicle frontal area $\left(\mathrm{m}^{2}\right)$ & 1.75 \\
Air density $\left(\mathrm{kg} / \mathrm{m}^{3}\right)$ & 1.22 \\
Fuel cell maximum net power $(\mathrm{kW})$ & 30 \\
Fuel cell average efficiency $(\%)$ & 56 \\
Battery maximum output power $(\mathrm{kW})$ & 20 \\
Battery maximum stored energy $(\mathrm{kW} \mathrm{h})$ & 9.25 \\
Battery initial SOC & 0.7 \\
Supercapacitor maximum output power $(\mathrm{kW})$ & 70 \\
Supercapacitor maximum stored energy $(\mathrm{Wh})$ & 350 \\
Supercapacitor initial SOC & 0.7 \\
Motor maximum power $(\mathrm{kW})$ & 75 \\
Motor maximum speed $(\mathrm{rpm})$ & 6283 \\
Motor average efficiency $(\%)$ & 90
\end{tabular}

Furthermore, fuel cell efficiency is shown in Figure 8. According to Figure 8, the proposed EMS can achieve and make the fuel cell operating efficiency over $55 \%$ during the most of whole drive cycle. It can be concluded that, with the proposed EMS, fuel cell system is controlled to operate in a high efficiency region, which can achieve good fuel economy by reducing hydrogen consumption. 


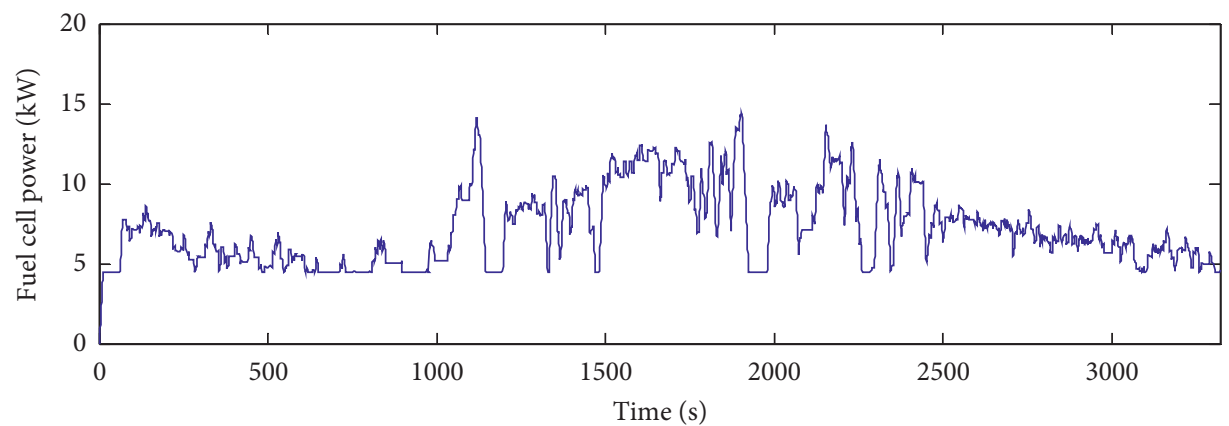

(a)

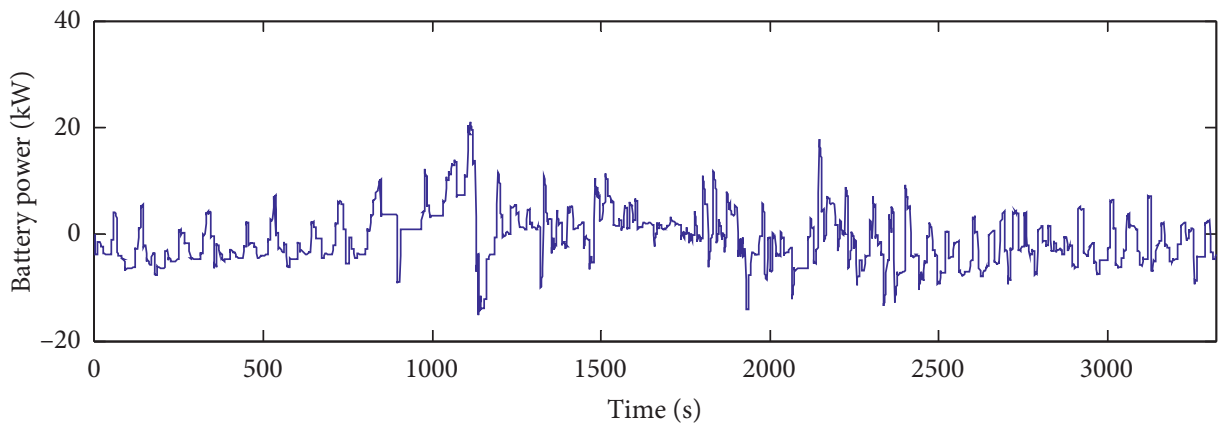

(b)

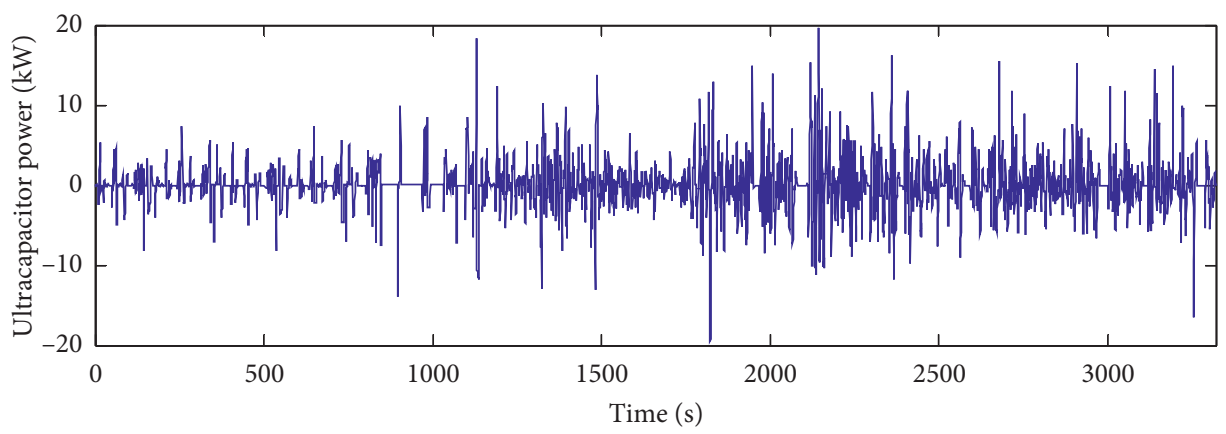

(c)

Figure 5: Power distribution of fuel cell, battery, and supercapacitor.

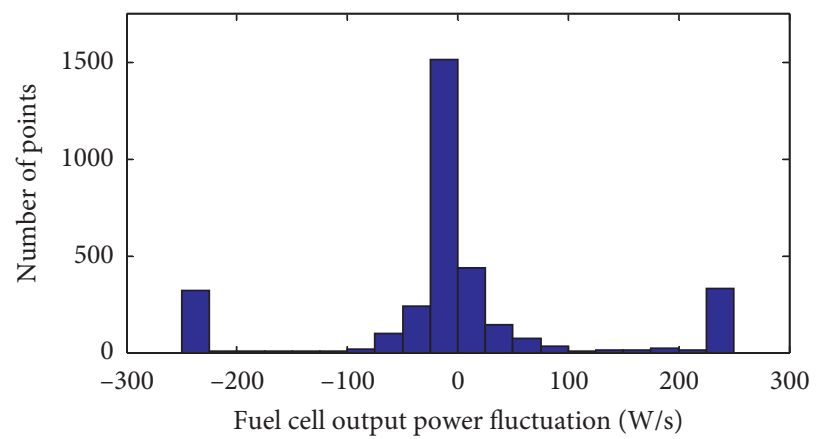

Figure 6: Fuel cell power fluctuation. 


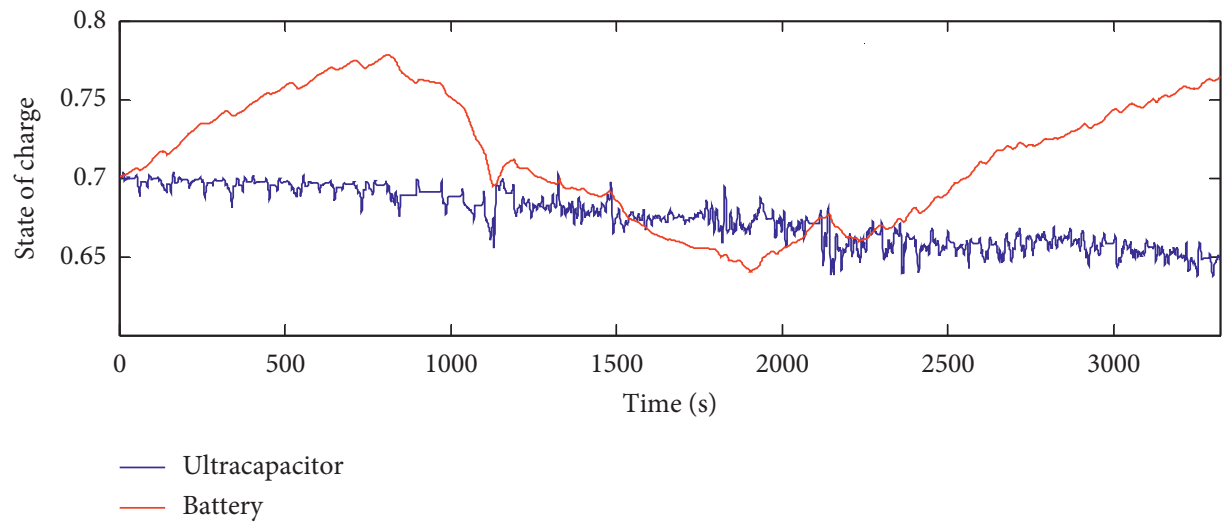

Figure 7: SOC of battery and supercapacitor.

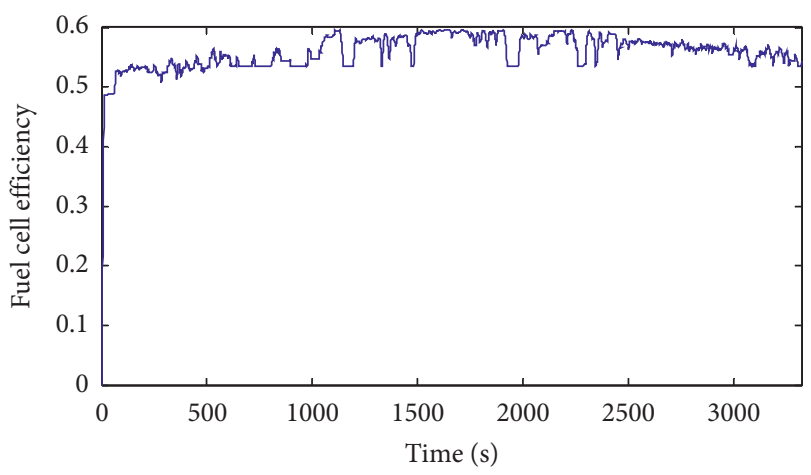

Figure 8: Fuel cell efficiency.

\section{Conclusions}

In this paper, energy management strategy using equivalent consumption minimization strategy is proposed for improving fuel cell efficiency and extending fuel cell lifespan. The proposed EMS separated required power into two components by WT. Supercapacitor is used to supply the high component of the required power to reduce the impact of load fluctuation on fuel cell and battery. The equivalent consumption minimization strategy is used to distribute the remaining low-frequency component power to fuel cell and battery for minimizing the hydrogen consumption. Simulation results show that the proposed EMS can effectively reduce fuel cell power fluctuation and limit it within $\pm 250 \mathrm{~W} / \mathrm{s}$, which is supposed to significantly extend fuel cell lifespan. Meanwhile, with the proposed EMS, fuel cell is guaranteed to operate in high efficiency ranges, which can achieve good fuel economy by reducing hydrogen consumption.

\section{Data Availability}

The data used to support the findings of this study are included within the article.

\section{Conflicts of Interest}

The authors declare that there are no conflicts of interest regarding the publication of this paper.

\section{Acknowledgments}

This work was partially supported by the National Natural Science Foundation of China (Grant no. 61473115), Scientific and Technological Innovation Leaders in Central Plains (Grant no. 194200510012), Science, Technology Innovative Teams in University of Henan Province (Grant no. 18IRTSTHN011), Key Scientific Research Projects of Universities in Henan Province (Grant nos. 19A413007 and 20A120008), National Thirteen-Five Equipment Pre-Research Foundation of China (Grant nos. 1403120207 and 61402100203), Aeronautical Science Foundation of China (Grant no. 20185142003), and Scientific and Technological Project of Henan Province (Grant no. 202102310200).

\section{References}

[1] A. Flah and C. Mahmoudi, "Design and analysis of a novel power management approach, applied on a connected vehicle as $\mathrm{V} 2 \mathrm{~V}, \mathrm{~V} 2 \mathrm{~B} / \mathrm{I}$, and $\mathrm{V} 2 \mathrm{~N}$," International Journal of Energy Research, vol. 43, no. 13, pp. 6869-6889, 2019.

[2] X. Li, Q. Wang, M. Liu et al., "Cooperative wireless-powered NOMA relaying for B5G IoT networks with hardware impairments and channel estimation errors," IEEE Internet of Things Journal, vol. 1, 2020.

[3] X. Li, H. Mengyan, Y. Liu, V. G. Menon, A. Paul, and Z. Ding, "I/Q imbalance aware nonlinear wireless-powered relaying of B5G networks: security and reliability analysis," IEEE Transactions on Network Science and Engineering, vol. 1, 2020.

[4] M. S. Alam, B. Hyde, P. Duffy, and A. McNabola, "Analysing the Co-Benefits of transport fleet and fuel policies in reducing PM2.5 and $\mathrm{CO}_{2}$ emissions," Journal of Cleaner Production, vol. 172, pp. 623-634, 2018.

[5] K. V. Koteswararao, G. N. Srinivasulu, and V. Venkateswarlu, "A review on energy allocation of fuel cell/battery/ultracapacitor for hybrid electric vehicles," International Journal of Energy Research, vol. 42, no. 14, pp. 4263-4283, 2018.

[6] H. Sun, Z. Fu, F. Tao, L. Zhu, and P. Si, "Data-driven reinforcement-learning-based hierarchical energy management strategy for fuel cell/battery/ultracapacitor hybrid electric vehicles," Journal of Power Sources, vol. 455, p. 227964, 2020.

[7] Y. J. Wang, Z. D. Sun, and Z. H. Chen, "Energy management strategy for battery/supercapacitor/fuel cell hybrid source vehicles based on finite state machine," Applied Energy, vol. 254, 2019. 
[8] X. Li, M. Zhao, Y. Liu, L. Li, Z. Ding, and A. Nallanathan, "Secrecy analysis of ambient backscatter NOMA systems under I/Q imbalance," IEEE Transactions on Vehicular Technology, vol. 69, no. 10, p. 12286, 2020.

[9] Y. Huang, H. Wang, A. Khajepour et al., "A review of power management strategies and component sizing methods for hybrid vehicles," Renewable and Sustainable Energy Reviews, vol. 96, pp. 132-144, 2018.

[10] X. Li, J. Li, Y. Liu, Z. Ding, and A. Nallanathan, "Residual transceiver hardware impairments on cooperative NOMA networks," IEEE Transactions on Wireless Communications, vol. 19, no. 1, pp. 680-695, 2020.

[11] Z. Fu, Z. Li, P. Si, and F. Tao, "A hierarchical energy management strategy for fuel cell/battery/supercapacitor hybrid electric vehicles," International Journal of Hydrogen Energy, vol. 44, no. 39, pp. 22146-22159, 2019.

[12] B. Ji, Z. Chen, S. Chen et al., "Joint optimization for ambient backscatter communication system with energy harvesting for IoT," Mechanical Systems and Signal Processing, vol. 135, 2020.

[13] X. Li, Q. Wang, Y. Liu, T. A. Tsiftsis, Z. Ding, and A. Nallanathan, "UAV-aided multi-way NOMA networks with residual hardware impairments," IEEE Wireless Communications Letters, vol. 9, no. 9, pp. 1538-1542, 2020.

[14] Z. Chen, N. Guo, J. Shen, R. Xiao, and P. Dong, "A hierarchical energy management strategy for power-split plug-in hybrid electric vehicles considering velocity prediction," IEEE Access, vol. 6, no. 2, pp. 33261-33274, 2018.

[15] Z. Z. Le, D. T. Qin, L. L. Hou et al., “An adaptive equivalent consumption minimization strategy for plug-in hybrid electric vehicles based on traffic information," Energy, vol. 190, 2020.

[16] S. Zhang, R. Xiong, and F. Sun, "Model predictive control for power management in a plug-inhybrid electric vehicle with a hybrid energy storage system," Applied Energy, vol. 185, pp. 1654-1662, 2015.

[17] Y. Huang, H. Wang, A. Khajepour, H. He, and J. Ji, "Model predictive control power management strategies for HEVs: a review," Journal of Power Sources, vol. 341, pp. 91-106, 2017.

[18] J. Guo, H. He, and J. Peng, "A novel MPC-based adaptive energy management strategy in plug-in hybrid electric vehicles," Energy, vol. 175, pp. 378-392, 2019.

[19] S. Zhang and R. Xiong, "Adaptive energy management of a plug-in hybrid electric vehicle based on driving pattern recognition and dynamic programming," Applied Energy, vol. 155, pp. 68-78, 2015.

[20] Z. Fu, L. Zhu, F. Tao, P. Si, and L. Sun, "Optimization based energy management strategy for fuel cell/battery/ultracapacitor hybrid vehicle considering fuel economy and fuel cell lifespan," International Journal of Hydrogen Energy, vol. 45, no. 15, pp. 8875-8886, 2020.

[21] A. Rezaei, J. B. Burl, B. Zhou, and M. Rezaei, "A new real-time optimal energy management strategy for parallel hybrid electric vehicles," IEEE Transactions on Control Systems Technology, vol. 27, no. 2, pp. 830-837, 2019.

[22] W. Zhang, J. Li, L. Xu, and M. Ouyang, "Optimization for a fuel cell/battery/capacity tram with equivalent consumption minimization strategy," Energy Conversion and Management, vol. 134, pp. 59-69, 2017.

[23] Z. Wang and X. Jiao, "Hierarchical model predictive control for hydraulic hybrid powertrain of a construction vehicle," Applied Sciences, vol. 10, no. 3, p. 745, 2020.

[24] C. Wang, R. Xiong, H. He, Y. Zhang, and W. Shen, "Comparison of decomposition levels for wavelet transform based energy management in a plug-in hybrid electric vehicle," Journal of Cleaner Production, vol. 210, pp. 1085-1097, 2019.

[25] Q. Zhang and G. Li, "A predictive energy management system for hybrid energy storage systems in electric vehicles," Electrical Engineering, vol. 101, no. 3, pp. 759-770, 2019. 